\title{
Routine Aircraft Airframe Spare Parts Inventory Analysis Used on Planned Maintenance at PT XYZ
}

\author{
Adhika Prajna Nandiwardhana ${ }^{1, *}$ Muslim Efendi Harahap ${ }^{1}$ \\ ${ }^{1}$ University of Indonesia \\ ${ }^{*}$ Corresponding author. Email: adhikaprajna@gmail.com
}

\begin{abstract}
Managing aircraft spare parts has been troublesome since there is demand uncertainty. Maintenance cost has been a concern nowadays especially spare parts cost. The objective of this research is to study costs generated by spare parts procurement using new inventory model compared with existing inventory model. To present this inventory analysis, a case study based on a maintenance, repair and overhaul (MRO) company in Indonesia is discussed. In this research, two methods are used, i.e. Syntetos-Boylan Approximation (SBA) and Single Exponential Smoothing (SES) to predict the planned maintenance forecasting. Furthermore, after forecasting has been done, inventory analysis is needed to determine inventory model to be implemented. According to inventory model, fixed order quantity is used to account for costs generated in procurement activity. Since the forecasting methods are new in PT XYZ, this gave different result compared to existing method. Suitable forecasting method is used on each SKU as the demand characteristics are different. The result of this research shows that the new inventory model using SBA and SES method are more accurate, and gave cost reduction $2.4 \%$ of total annual procurement cost compared to existing inventory model. It can be said that the method can be applied to improve inventory cost reduction to face challenges in aviation industry. The weakness of this research is only conducted in several spare part SKUs with specific demand characteristics. To prove that the method can be generally accepted, the number of SKU samples needs to be increased.
\end{abstract}

Keywords - Inventory analysis, forecasting, planned maintenance

\section{INTRODUCTION}

The development of the commercial aviation industry in the next 20 years is predicted to increase the number of consumers using aviation services [1]. In the future (2030), Indonesia will rank fourth in this industry with growth of $9 \%$ per year. Operational activities of aircraft flights have costs consisting of several things such as key operating costs that must be incurred by the airlines. One of them is that maintenance and overhaul costs accounted for almost $10 \%$ of the total operational costs. According to maintenance costs, spare parts contributes for $13 \%$ of it [2]. In maintenance activities, it is necessary to instill lean management principles to focus on minimizing existing waste (the source of spare parts, equipment and labor) [3].

Aircraft maintenance activities at PT XYZ are carried out based on the event maintenance planning of each aircraft. In the process of maintenance scheduling, it is based on the maintenance program that already owned. Actual conditions in the procurement of spare parts become difficult due to a lack of ability to adjust aircraft maintenance events.
There are remaining spare parts inventories that have not been consumed yet according to purchasing historical data from January 2016 to December 2019. Hence, optimizing aircraft parts forecasting and managing inventory are the focus of this research. ABC Analysis is used in spare parts classification to identify high contribution spare parts to the entire inventory. Furthermore, yearly planned maintenance data is used as a forecasting reference. Since moving average method is used in existing forecasting method, averaged all demand in every period could not achieve good accuracy. Hence, it affects inventory model parameter and have a direct impact on costs.

In this paper, $\mathrm{ABC}$ Analysis is used to classify spare parts inventory. Approach used in the forecasting side are single exponential smoothing (SES) and syntetos-boylan approximation (SBA) to analyze spare parts demand classified in planned maintenance events. Error rate on the forecasting side is counted to discover accuracy of the method. On the inventory management side, fixed-order quantity method is used. To count the total cost in procurement activity, ordering cost, shipment cost and 
holding cost should be defined so that total cost could be countable.

The main target of this paper is comparing the proposed method with the existing method in PT XYZ. Defining spare parts to be analyzed is based on inventory classification and planned maintenance events. Furthermore, spare parts forecasting conducted as a basis for inventory model analysis. The major point of this research is comparing between new inventory model and existing inventory model. Hence, total cost difference could be generated by counting total cost of each method to discover efficiency in procurement activity.

\section{MATERIALS AND METHODS}

\subsection{Literature Review}

Aircraft maintenance process is carried out to restore the reliability of the aircraft so that it remains airworthy with a minimum cost, where MRO companies are targeting to achieve high service levels and to maximize profits through service efficiency and cost reduction through scheduled tasks and unscheduled tasks maintenance [4]. Periodic maintenance is one of the maintenance processes carried out following scheduled intervals and periods. This maintenance is based on manufacturing recommendations or prior experience data [5]. Every aircraft proposal stated delivery date of the aircraft, including workload and estimated costs for scheduled and unscheduled maintenance. In the process of planning the work is determined scheduling in order to adjust resources to do maintenance and determined the time frame of work to be completed [4].

In the operational process, it is needed to maintain inventory supply for operational sustainability, meet various demands, facilitate flexibility in production scheduling, provide security due to varying delivery times and provide advantages for economical order size purchases [6]. Inventory in the aviation industry traditionally classified into four spare parts groups: Rotable, Repairable, Expendables, and Consumables. Regarding Expendables and Consumables, reorder point (ROP) systems are used and the input comes from historical requests with estimated changes [7]. In making decisions that affect inventory, there are several costs that must be taken into account such as holding / carrying costs, setup / production change costs, ordering costs and shortage costs [8].

To do an inventory analysis, $\mathrm{ABC}$ Analysis is needed which divides on-hand inventory into three classifications based on the value of the inventory. Determining inventory classification is needed, such as determining class A, class $\mathrm{B}$ and class $\mathrm{C}$ [6]. On the forecasting side, SES method is quite common in various literature about forecasting lumpy demand [9]. This method is a fairly simple because it only takes into account the demand size in each period and updates the forecast of the demand in each calculated period. Other than that, SBA method in this research uses a linear reduction factor in the smoothing constant used when updating demand intervals [10]. Thus, the results of this method are vary depending on the level of data aggregation (weekly, monthly, quarterly) and the type of demand pattern (ranging from subtle to very disjointed) [11].

Forecasting process can be evaluated by measuring the error rate or standard deviation. The performance of the forecasting method used can be evaluated through the calculation of mean absolute deviation (MAD) and Mean Squared Error (MSE) by measuring the overall error in the forecast [6]. Furthermore, alternative way can be done by using the mean absolute percentage error (MAPE) to overcome the problems encountered when using MAD and MSE. However, lumpy conditions make MAPE calculations difficult due to zero-demand conditions so that different MAD / A calculations are used and can be used when there is zero demand [12].

Creating model of inventory management can be done with the fixed-order quantity model (model Q), where it is necessary to determine the reorder point, $\mathrm{R}$ and order size, Q. Hence, the total cost can be calculated by adding up all the costs incurred during the process of purchasing spare parts [8].

\subsection{Research Methods}

To analyze spare parts in PT XYZ inventory, historical data are collected. Data used in this research are purchase order history from January 2016 until December 2019 and spare parts demand history. ABC Analysis is used to classify spare parts value proportion to discover spare parts in category A (represents $80 \%$ of the total inventory value), category B (represents about $15 \%$ to $25 \%$ of the total inventory value) and category $\mathrm{C}$ (represents only $5 \%$ of the total inventory value). Then, spare parts in category A are identified to find out whether there is a demand in planned maintenance or not.

Demand forecasting in this research is calculated using Single Exponential Smoothing (SES) as follows.

$D_{t}^{\prime}=D_{t-1}^{\prime}+\alpha\left(D_{t}-D_{t-1}^{\prime}\right)$

Another method used in this research is SyntetosBoylan Approximation (SBA). In SBA, if the demand at time $t$ is 0 , the estimated value of future demand will remain the same as the initial conditions. The calculations on this method can be showed as follows.

$D_{t}^{\prime}=\left(1-\frac{\beta}{2}\right) \frac{Z_{t}^{\prime}}{T_{t}^{\prime}}$

Where,

If

$D_{t}>0: Z_{t}^{t}=Z_{t-1}^{s}+\alpha\left(Z_{t}-Z_{t-1}^{t}\right)$

And

$T_{t}^{\prime}=T_{t-1}^{\prime}+\beta\left(T_{t}-T_{t-1}^{\prime}\right)$

Otherwise,

$Z_{t}^{v}=Z_{t-1}^{v}$ and $T_{t}^{\prime}=T_{t-1}^{v}$

The forecasting process can be evaluated by measuring the error rate or standard deviation. The performance of the forecasting method used can be evaluated through the calculation of mean absolute deviation (MAD) and Mean Squared Error (MSE) by 
measuring the overall error in the forecast. The calculations on MAD and MSE can be showed as follows.

$$
\begin{aligned}
& M A D=\frac{\sum \mid \text { Actual }- \text { Forecast } \mid}{n} \\
& \text { MSE }=\frac{\left.\sum \text { (Forecast Errors }\right)^{2}}{n}
\end{aligned}
$$

After the forecasting process is completed, a proposed inventory management model is carried out using the Fixed Order Quantity methods to determine the total costs incurred during the procurement process. Fixed Order Quantity model has a way to determine a certain point, $\mathrm{R}$, where the order will be placed and the order size is, Q. The total cost can be calculated by adding up all the costs incurred during the process of spare parts procurement.

$$
\begin{aligned}
& T c=D \cdot C+\frac{D}{Q o p t} S+H \frac{(Q o p t+R-\bar{D} \cdot L)}{2} \\
& Q_{\text {opt }}=\sqrt{\frac{2 D S}{H}}
\end{aligned}
$$

The final step in this research is to compare the total costs incurred in the process of spare parts procurement activities.

\section{RESULTS}

\subsection{Inventory Classification}

Spare parts classification in this research is based on on-hand inventory in PT XYZ. Spare parts intended for planned maintenance event is analyzed because the parts are directly related to the planned maintenance made by the Aircraft Maintenance Planner in accordance with the discussion. So that, value of the spare parts obtained for the total inventory value of $\$ 3,715,637.48$.

Based on the classification of spare parts categories through ABC analysis, it can be seen in the Table 1 that from the Airframe spare parts of the planned maintenance category there are 414 SKUs that are in category Class A having an inventory value of $\$ 2,971,425.21$. After selecting the SKUs contained in planned maintenance in 2018-2020, 29 SKUs were obtained.

Table 1. Airframe Spare Parts Classification

\begin{tabular}{|c|c|c|c|}
\hline Category & Inventory Value & Percentage & $\begin{array}{c}\text { Number of } \\
\text { SKU }\end{array}$ \\
\hline $\mathrm{A}$ & $\$ 2,971,425.21$ & $80 \%$ & 414 \\
\hline $\mathrm{B}$ & $\$ 558,286.25$ & $15 \%$ & 566 \\
\hline $\mathrm{C}$ & $\$ 185,926.02$ & $5 \%$ & 1815 \\
\hline Grand Total & $\$ \mathbf{3 , 7 1 5 , 6 3 7 . 4 8}$ & $\mathbf{1 0 0 \%}$ & $\mathbf{2 7 9 5}$ \\
\hline
\end{tabular}

\subsection{Forecasting Result}

In the forecasting method used, the SBA method requires determining the values of $\alpha$ and $\beta$ as smoothing parameters in the range of values $0 \leq \alpha \leq 1$ and $0 \leq \beta$ $\leq 1$. Determination of these parameters is done by trial and error. This is to get the right combination of $\alpha$ and $\beta$ with the smallest error rate. In addition, SES forecasting method is used for all SKUs which have the same notation as the SBA method. A comparison between forecasting methods using SBA and SES is required with the existing forecasting method, Moving Average (MA).

What can be done is to compare the forecast error rate between the new forecasting methods and the existing ones. The error rates compared were MAD and MSE. Measurement of error rate using MAPE is not used because there is zero demand in the SKU, so it cannot be calculated. Through this comparison, we can find out which forecasting method is better in each SKU analyzed as showed on Appendix.

\subsection{Inventory Model Analysis}

The inventory management model used is the FixedOrder Quantity model. In each inventory management model, it has a mathematical equation of total costs so that it can be seen that the component costs are the cost of the parts themselves, ordering costs and holding costs. To find out the cost of purchasing spare parts, it is necessary to identify the price per unit of each SKU. This method can be done by dividing the value of inventory by the amount or quantity of the inventory. While ordering costs can be determined through several cost components such as employee salary costs and shipping costs.

To determine employee salary costs, salaries of all employees involved in the planning spare parts procurement in a year can be divided proportionally to each spare parts according to inventory value. Meanwhile, to find out the shipping costs, this is carried out based on the purchase history of each part. The fee is taken based on the last purchase made. To calculate the cost of storage, it can be done by calculating the area of packaging of spare parts multiplied by the rate of storage costs.

In Fixed Order Quantity model, the ordering of spare parts is carried out with the optimal quantity (Qopt) for each order, so that the optimal quantity or what is commonly called the Economic Order Quantity needs to be determined. Having a probabilistic demand, making this inventory management model must use a type of probabilistic. However, no backorder is allowed to make these parameters ignored.

After performing an optimal quantity calculation, an inventory management model can be designed for each spare parts SKU with different detailed calculation data. Using cost data, demand data, and other data that has been calculated, the total costs incurred in the procurement of spare parts using the Fixed Order Quantity inventory management model can be determined. Using the existing mathematical equation, the results of the total costs incurred for each spare parts procurement can be seen in the Table 2 . 
Table 2. Total Annual Cost Each SKU

\begin{tabular}{|c|c|c|}
\hline SKU & \multicolumn{2}{|c|}{ TOTAL COST } \\
\hline HONEYBEE60 & $\$$ & $156,861.95$ \\
\hline 8-933-01 & $\$$ & $22,781.88$ \\
\hline LD4 & $\$$ & $490,633.64$ \\
\hline 3036376 & $\$$ & $24,659.55$ \\
\hline CH34736 & $\$$ & $306,302.64$ \\
\hline A5735012020000 & $\$$ & $19,734.59$ \\
\hline 7513128 & $\$$ & $4,567.99$ \\
\hline P603152 & $\$$ & 749.97 \\
\hline $240 \mathrm{AC}$ & $\$$ & $10,823.29$ \\
\hline $3059253-01$ & $\$$ & $38,081.35$ \\
\hline BE28990 & $\$$ & $12,216.84$ \\
\hline GA68100090007 & $\$$ & $52,443.56$ \\
\hline QA07995 & $\$$ & $87,079.70$ \\
\hline PS870B2 & $\$$ & $378,036.87$ \\
\hline $649-387-240-0$ & $\$$ & $21,243.24$ \\
\hline MOLYKOTE33M & $\$$ & $3,784.85$ \\
\hline MEBROM & $\$$ & $7,537.04$ \\
\hline ALODINE1200S & $\$$ & $9,828.69$ \\
\hline ARDROXAV8 & $\$$ & $7,897.95$ \\
\hline PUROGENE & $\$$ & $2,053.29$ \\
\hline APPLIED2-225 & $\$$ & $63,053.67$ \\
\hline ARDROXAV100D & $\$$ & $2,486.70$ \\
\hline PS890A2 & $\$$ & $24,529.34$ \\
\hline AIREZ & $\$$ & $16,674.78$ \\
\hline 1014302 & $\$$ & $114,016.98$ \\
\hline AEROSHELL-LGF & $\$$ & $85,972.20$ \\
\hline MS-SNOOP-8OZ & $\$$ & $19,295.03$ \\
\hline ST3086-013 & $\$$ & $10,754.94$ \\
\hline 33370 & $\$$ & $247,193.41$ \\
\hline
\end{tabular}

The total cost of each SKU varies. This is due to differences in cost components such as parts costs, ordering costs, and storage costs. Each SKU has a different form and unit that affects the calculation of these costs.

\section{DISCUSSION}

The results of forecasting requests that have been made are compared to the existing methods. Through this comparison the most appropriate method can be determined based on the smallest forecast error rate as showed in the Appendix Table.

After knowing the inventory management model formulation, total costs incurred in procurement are known. The inventory management model with new method is supported by forecasting the SBA and SES methods. On the other hand, the model with existing method is using Moving Average method but still uses the Fixed Order Quantity model. As a comparison of total costs is needed, inventory management models using new method and existing method are compared and the results can be seen in the Table 3 .

From the Table 3, it can be seen the amount of cost reduction of the entire SKUs using the proposed inventory model. For the entire SKUs studied, the annual cost reduction can reach $\$ 54,939.00$ or $2.4 \%$ of the annual cost (see Table 4). This efficiency is relatively large in the procurement of parts so that it can reduce company expenses and increase the profitability.
Table 3. Total Annual Cost Each SKU Comparation

\begin{tabular}{|c|rr|rr|}
\hline SKU & \multicolumn{2}{|c|}{$\begin{array}{c}\text { Total Cost New } \\
\text { Method }\end{array}$} & \multicolumn{1}{c|}{$\begin{array}{c}\text { Total Cost } \\
\text { Existing } \\
\text { Method }\end{array}$} \\
\hline HONEYBEE60 & $\$$ & $156,861.95$ & $\$$ & $159,534.93$ \\
\hline $8-933-01$ & $\$$ & $22,781.88$ & $\$$ & $20,918.04$ \\
\hline LD4 & $\$$ & $490,633.64$ & $\$$ & $532,443.20$ \\
\hline C3636376 & $\$$ & $24,659.55$ & $\$$ & $25,196.40$ \\
\hline CH34736 & $\$$ & $306,302.64$ & $\$$ & $310,577.84$ \\
\hline A5735012020000 & $\$$ & $19,734.59$ & $\$$ & $27,521.98$ \\
\hline 7513128 & $\$$ & $4,567.99$ & $\$$ & $3,686.96$ \\
\hline P603152 & $\$$ & 749.97 & $\$$ & $3,939.98$ \\
\hline $240 A C$ & $\$$ & $10,823.29$ & $\$$ & $13,482.55$ \\
\hline 3059253-01 & $\$$ & $38,081.35$ & $\$$ & $34,388.04$ \\
\hline BE28990 & $\$$ & $12,216.84$ & $\$$ & $18,980.64$ \\
\hline GA68100090007 & $\$$ & $52,443.56$ & $\$$ & $41,403.67$ \\
\hline QA07995 & $\$$ & $87,079.70$ & $\$$ & $84,868.58$ \\
\hline PS870B2 & $\$$ & $378,036.87$ & $\$$ & $359,041.42$ \\
\hline 649-387-240-0 & $\$$ & $21,243.24$ & $\$$ & $24,881.29$ \\
\hline MOLYKOTE33M & $\$$ & $3,784.85$ & $\$$ & $4,533.55$ \\
\hline MEBROM & $\$$ & $7,537.04$ & $\$$ & $9,865.78$ \\
\hline ALODINE1200S & $\$$ & $9,828.69$ & $\$$ & $11,171.11$ \\
\hline ARDROXAV8 & $\$$ & $7,897.95$ & $\$$ & $7,601.99$ \\
\hline PUROGENE & $\$$ & $2,053.29$ & $\$$ & $3,509.96$ \\
\hline APPLIED2-225 & $\$$ & $63,053.67$ & $\$$ & $68,900.83$ \\
\hline ARDROXAV100D & $\$$ & $2,486.70$ & $\$$ & $2,499.80$ \\
\hline PS890A2 & $\$$ & $24,529.34$ & $\$$ & $32,204.79$ \\
\hline AIREZ & $\$$ & $16,674.78$ & $\$$ & $17,865.91$ \\
\hline 1014302 & $\$$ & $114,016.98$ & $\$$ & $136,442.03$ \\
\hline AEROSHELL-LGF & $\$$ & $85,972.20$ & $\$$ & $83,139.49$ \\
\hline MS-SNOOP-8OZ & $\$$ & $19,295.03$ & $\$$ & $27,517.88$ \\
\hline ST3086-013 & $\$$ & $10,754.94$ & $\$$ & $6,435.08$ \\
\hline 33370 & $\$$ & $247,193.41$ & $\$$ & $223,681.20$ \\
\hline & & & & \\
\hline & & &
\end{tabular}

Table 4. Total Annual Cost Comparation and Annual Cost Saving

\begin{tabular}{|c|c|c|}
\hline New Method & Existing Method & Annual Cost Saving \\
\hline$\$ 2,241,295.91$ & $\$ 2,296,234.91$ & $\$ 54,939.00$ \\
\hline
\end{tabular}

\section{CONCLUSION}

In conclusion, based on the research that has been carried out regarding the analysis of routine aircraft airframe spare parts inventory used in planned maintenance at PT XYZ, the use of SES and SBA forecasting methods generally shows advantages over the MA methods that have been used by companies based on the calculated error rate. Furthermore, analysis of spare parts inventory using the fixed order quantity method shows the level of costs generated in the procurement of PT XYZ parts. In the end, the use of the proposed method can be superior to existing methods, this is evidenced by the calculation of the total costs generated between these methods which lead to an efficiency.

\section{ACKNOWLEDGMENTS}

We thank all employees in PT XYZ for their support, data and valuable input to this research. So that, this research can be completed well. 


\section{REFERENCES}

[1] IATA (2018). IATA Forecast Predicts 8.2 billion Air Travelers in 2037 (https://www.iata.org/pressroom/pr/Pages/2018-10-2402.aspx). Access date 12 Nov 19. J. Clerk Maxwell, A Treatise on Electricity and Magnetism, 3rd ed., vol. 2. Oxford: Clarendon, 1892, pp.68-73.

[2] IATA (2017). IATA Economics' Chart Of The Week.

[3] Stadnicka, D., \& Ratnayake, R. M. C. (2017). Enhancing Aircraft Maintenance Services: A VSM Based Case Study. Procedia Engineering, 182, 665-672. doi:10.1016/j.proeng.2017.03.177

[4] Dinis, D., Barbosa-Póvoa, A., \& Teixeira, Â. P. (2019). A supporting framework for maintenance capacity planning and scheduling: Development and application in the aircraft MRO industry. International Journal of Production Economics, 218, 115. doi:10.1016/j.ijpe.2019.04.029

[5] AIDC Cape Soc, Ltd. (2014). Total Productive Maintenance Planned Maintenance Step 2. AIDC.

[6] Heizer, Jay, Barry Render dan Chuck Munson (2017). Operations Management: Sustainability and Supply Chain Management. Pearson.

[7] Gu, J., Zhang, G., \& Li, K. W. (2015). Efficient aircraft spare parts inventory management under demand uncertainty. Journal of Air Transport Management, 42, 101-109. doi:10.1016/j.jairtraman.2014.09.006

[8] Jacobs, F. Robert dan Richard B. Chase (2018). Operations and Supply Chain Management. McGraw Hill Education.

[9] Gutierrez, R. S., Solis, A. O., \& Mukhopadhyay, S. (2008) Lumpy demand forecasting using neural networks. International Journal of Production Economics, 111(2), 409-420. doi:10.1016/j.ijpe.2007.01.007

[10] Babai, M. Z., Dallery, Y., Boubaker, S., \& Kalai, R. (2019). A new method to forecast intermittent demand in the presence of inventory obsolescence. International Journal of Production Economics, 209, 30-41. doi:10.1016/j.ijpe.2018.01.026

[11] Syntetos, A. A., Zied Babai, M., \& Gardner, E. S. (2015) Forecasting intermittent inventory demands: simple parametric methods vs. bootstrapping. Journal of Business Research, 68(8), 1746-1752. doi:10.1016/j.jbusres.2015.03.034

[12] Regattieri, A., Gamberi, M., Gamberini, R., \& Manzini, R. (2005). Managing lumpy demand for aircraft spare parts. Journal of Air Transport Management, 11(6), 426-431. doi:10.1016/j.jairtraman.2005.06.003 


\section{APPENDIX}

Table 5. Total Annual Cost Comparation and Annual Cost Saving

\begin{tabular}{|c|c|c|c|c|c|c|c|c|c|c|}
\hline \multirow{2}{*}{ SKU } & \multicolumn{4}{|c|}{ SBA } & \multicolumn{3}{|c|}{ SES } & \multicolumn{2}{|c|}{ Moving Average (Existing) } & \multirow{2}{*}{$\begin{array}{c}\text { Best } \\
\text { Method }\end{array}$} \\
\hline & $\boldsymbol{\alpha}$ & $\beta$ & MAD & MSE & $\boldsymbol{\alpha}$ & MAD & MSE & MAD & MSE & \\
\hline HONEYBEE60 & & & & & 0.10 & 1071.88 & 2631396.123 & 1181.95 & 3313516.47 & SES \\
\hline $8-933-01$ & 0.1 & 0.1 & 1.42 & 2.651 & 0.10 & 1.42 & 2.625 & 1.57 & 3.56 & SES \\
\hline LD4 & & & & & 0.10 & 975.32 & 1166066.102 & 1106.42 & 1539776.36 & SES \\
\hline 3036376 & 0.1 & 0.1 & 2.33 & 15.505 & 0.10 & 2.52 & 15.499 & 3.03 & 19.77 & SES \\
\hline CH34736 & 0.7 & 0.1 & 5.04 & 41.895 & 0.70 & 5.00 & 41.974 & 6.11 & 53.47 & SBA \\
\hline A5735012020000 & 0.1 & 0.1 & 33.96 & 2320.864 & 0.10 & 34.56 & 2319.889 & 38.11 & 2863.00 & SES \\
\hline 7513128 & & & & & 0.10 & 13.86 & 437.393 & 13.64 & 440.15 & SES \\
\hline $\mathrm{P} 603152$ & 0.9 & 0.3 & 0.22 & 0.266 & 0.10 & 0.37 & 0.268 & 0.33 & 0.34 & SBA \\
\hline $240 \mathrm{AC}$ & 0.1 & 0.5 & 0.28 & 0.212 & 0.10 & 0.32 & 0.210 & 0.35 & 0.26 & SES \\
\hline $3059253-01$ & 0.1 & 0.1 & 2.71 & 11.318 & 0.10 & 2.76 & 11.414 & 2.99 & 13.70 & SBA \\
\hline BE28990 & 0.7 & 0.3 & 1.84 & 5.065 & 0.70 & 1.89 & 5.265 & 1.90 & 6.14 & SBA \\
\hline GA68100090007 & & & & & 0.30 & 795647.26 & 800744701486.033 & 753335.56 & 911764410384.37 & SES \\
\hline QA07995 & & & & & 0.10 & 3.30 & 21.043 & 3.94 & 27.76 & SES \\
\hline PS870B2 & & & & & 0.10 & 74.87 & 8439.038 & 78.56 & 10645.25 & SES \\
\hline $649-387-240-0$ & 0.9 & 0.7 & 7.41 & 116.755 & 0.10 & 8.44 & 114.516 & 9.79 & 160.09 & SES \\
\hline MOLYKOTE33M & 0.1 & 0.9 & 8.55 & 304.882 & 0.10 & 11.10 & 307.987 & 11.99 & 415.34 & SBA \\
\hline MEBROM & 0.1 & 0.1 & 59.53 & 7732.385 & 0.10 & 63.11 & 7744.887 & 70.47 & 10543.93 & SBA \\
\hline ALODINE1200S & 0.1 & 0.1 & 13.29 & 228.757 & 0.10 & 13.42 & 228.675 & 16.08 & 338.65 & SES \\
\hline ARDROXAV8 & 0.1 & 0.3 & 17.30 & 1040.501 & 0.10 & 18.79 & 1019.965 & 21.57 & 1322.33 & SES \\
\hline PUROGENE & 0.3 & 0.3 & 15.01 & 1514.532 & 0.30 & 15.99 & 1525.676 & 16.76 & 1645.84 & SBA \\
\hline APPLIED2-225 & 0.5 & 0.3 & 444.02 & 308235.403 & 0.10 & 449.80 & 290824.266 & 470.27 & 333006.50 & SES \\
\hline ARDROXAV100D & 0.3 & 0.9 & 2.64 & 36.398 & 0.30 & 3.04 & 33.237 & 2.78 & 32.87 & MA \\
\hline PS890A2 & 0.1 & 0.1 & 8.94 & 128.846 & 0.10 & 9.01 & 128.041 & 10.38 & 169.22 & SES \\
\hline AIREZ & & & & & 0.10 & 10.02 & 289.359 & 12.46 & 414.99 & SES \\
\hline 1014302 & & & & & 0.30 & 10.34 & 173.487 & 11.43 & 209.50 & SES \\
\hline AEROSHELL-LGF & & & & & 0.10 & 382.70 & 201677.374 & 445.44 & 288977.62 & SES \\
\hline MS-SNOOP-8OZ & & & & & 0.70 & 114.36 & 21139.814 & 119.31 & 21901.48 & SES \\
\hline ST3086-013 & 0.1 & 0.7 & 3.90 & 26.878 & 0.10 & 4.05 & 24.492 & 4.31 & 28.87 & SES \\
\hline 33370 & & & & & 0.10 & 37.90 & 2829.299 & 44.08 & 3493.80 & SES \\
\hline
\end{tabular}

